\title{
Associação entre cagA e alelos do vacA de Helicobacter pylori e úlcera duodenal em crianças no Brasil
}

\author{
VacA alleles, cagA, and duodenal ulcer in children in Brazil
}

\author{
Abdussalam Ali Ramadam Ashour ${ }^{1,5}$ \\ Valquíria Ribeiro de Gusmão ${ }^{1}$ \\ Paula Prazeres Magalhães ${ }^{2}$ \\ Guilherme Birchal Collares ${ }^{3}$ \\ Edilberto Nogueira Mendes ${ }^{4}$ \\ Dulciene Maria de Magalhães Queiroz ${ }^{6}$ \\ Gifone Aguiar Rocha ${ }^{6}$ \\ Andreia Maria Camargos Rocha ${ }^{6}$ \\ Anfrisina Sales Teles Carvalho ${ }^{7}$
}

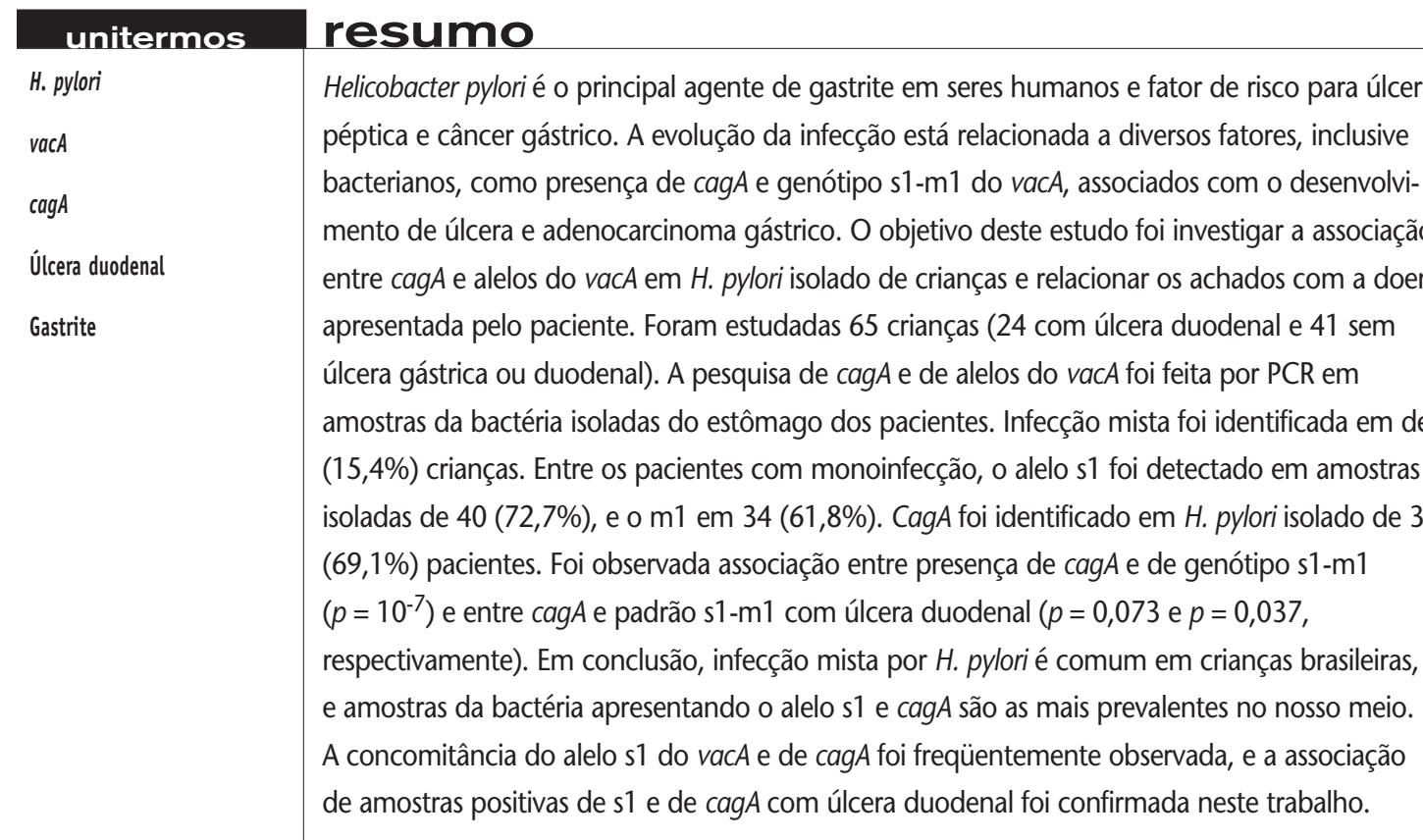

\section{abstract}

Helicobacter pylori is now accepted as the most important agent of gastritis in humans and as a risk factor for ulcer disease and gastric carcinoma ethiopathogenesis. The outcome of the infection

is associated with several factors, among them bacterial ones such as cagA and vacA s 1

genotype. We aimed to investigate the association between cagA and vacA genotypes in $\mathrm{H}$. pylori strains isolated from children and to correlate these findings with patient's disease. A total of 65 children (24 with duodenal ulcer and 41 without gastric or duodenal ulcer) were included in

the study. CagA and vacA alleles were identified by PCR in bacterium strains isolated from the gastric mucosa of the studied group. Multiple-strain infection was detected in 10 (15.4\%) patients. Among children with nonmixed infection, s1 allele was found in $\mathrm{H}$. pylori strains isolated from 40 (72.7\%), and $m 1$ allele in strains obtained from 34 (61.8\%). CagA was found in bacterium strains isolated from 38 (69.1\%) patients. Association between cagA and s1-m1 genotype $\left(p=10^{-7}\right)$, and between these genotypes and duodenal ulcer $(p=0.073$ and $p=0.037$, respectively) was observed. In conclusion, multiple-strain infection is frequent in Brazilian children. $\mathrm{H}$. pylori strains harbouring, simultaneously, cagA and vacA s1-m1 genotypes are the most frequent in our pediatric population and are associated to ulcer disease.

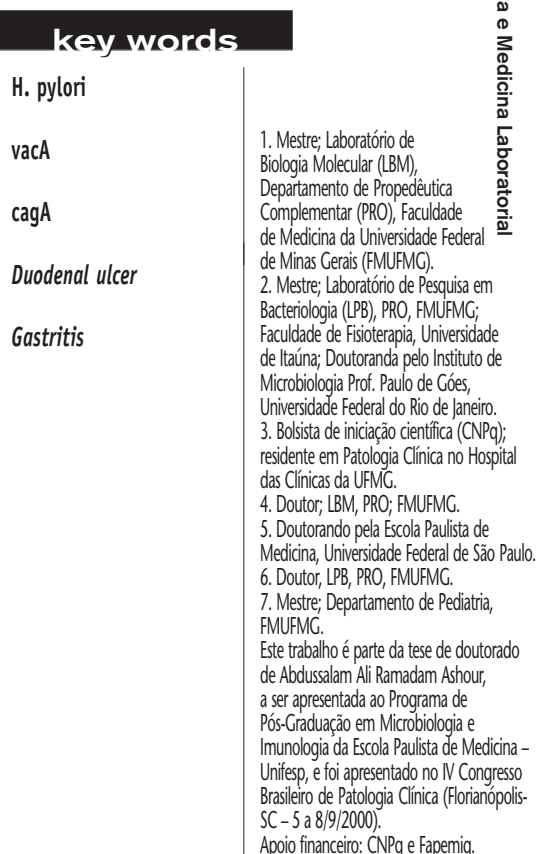




\section{Introdução}

Desde sua descoberta, na década de 80, Helicobacter pylori, bactéria espiralada gram-negativa, tem sido associada à etiopatogenia de diversas doenças do aparelho digestivo (17). Atualmente, o microrganismo é considerado o mais importante agente etiológico de gastrite em seres humanos, um fator essencial na gênese da úlcera péptica (20) e um fator de risco para o desenvolvimento de câncer gástrico (13), sendo considerado, pela Organização Mundial de Saúde, carcinógeno do tipo 1 (31). Há, ainda, evidências de sua associação com linfoma gástrico do tipo Malt e com linfoma não-Hodgkin gástrico (11). A evolução da infecção está associada a diversos fatores, entre eles tempo de infecção (13), fatores do hospedeiro (4) e fatores de patogenicidade da bactéria $(1-3,6,7,10,15$, $19,23-25,28,30-32)$. Acredita-se que a aquisição da bactéria precocemente na infância e a conseqüente infecção de longa duração sejam fatores importantes associados ao desenvolvimento de carcinoma gástrico (13). Fatores do hospedeiro incluem resposta imune celular e humoral, genética HLA e grupo sangüíneo (4). Entre os fatores de patogenicidade da bactéria podem-se citar a produção de grande quantidade de urease, os fatores de adesão e a produção de citotoxina vacuolizante, entre outros (1-3, $6,7,10,12,15,16,23-26,28,30-32)$. Nos últimos anos vem se intensificando a pesquisa de marcadores de patogenicidade, por técnicas moleculares, na tentativa de detectar amostras da bactéria especificamente associadas a cada uma dessas doenças. Entre estes marcadores, o cagA e os alelos do vacA têm sido amplamente estudados (1-3, $6,12,15,16,18,19,22-24,27-30,32,33)$.

O cagA (cytotoxin-associated gene A) foi o primeiro marcador genético detectado em amostras da bactéria. Codifica a proteína $\operatorname{cagA}$ e está presente, mais freqüentemente, em amostras isoladas de pacientes com úlcera péptica do que nas obtidas de pacientes com gastrite (9). Uma das explicações para o fato é que o cagA é um marcador de uma ilha de patogenicidade, composta por mais de 30 genes, que está associada à indução de resposta inflamatória mais intensa (7). Assim, o cagA é um marcador de um grupo de amostras mais virulentas de $H$. pylori associadas, mais comumente, com úlcera péptica e câncer gástrico $(9$, $12,16,19,23,24,28,30,32,33)$, e sua detecção tem se mostrado clinicamente relevante, ao menos na maioria dos países do Ocidente $(12,16,24,28,32)$.

$\mathrm{O}$ vacA (vacuolating cytotoxin gene $A$ ) é o gene que codifica a produção da citotoxina vacuolizante, conside- rada importante fator na etiopatogênese da úlcera péptica $(1,10,25)$. Apesar de o gene estar presente em todas as amostras da bactéria, apenas aproximadamente metade delas produz vacuolização celular in vitro $(1,10)$, o que sugere a existência de diversidade genética. De fato, Atherton et al. (1) demonstraram, em 1995, a existência de duas famílias de seqüências sinalizadoras (s1 e s2) e duas de seqüências médias ( $\mathrm{m} 1 \mathrm{e} \mathrm{m} 2$ ) do vacA. Os autores demonstraram que o alelo $s 1$ está relacionado à produção de citotoxina, e o alelo $\mathrm{m} 1$, à produção de maior quantidade da proteína. Assim, os genótipos s1-m1 e s1-m2 codificam a produção de citotoxina, e o s2-m2 está presente em amostras não-citotóxicas (1). Os genótipos s1-m1 e s1-m2 são mais freqüentemente detectados em amostras de $\mathrm{H}$. pylori isoladas de pacientes com úlcera péptica, e amostras s2-m2 são mais comumente isoladas de pacientes com gastrite $(1,3,12,15,28,32,33)$. De forma semelhante ao $\operatorname{cag} A(22,32,33)$, a investigação do padrão de alelos do vacA tem se mostrado clinicamente relevante, exceto em pacientes de origem oriental $(28,32,33)$.

Nos últimos anos, a associação entre presença de $\operatorname{cag} A$, seqüência sinalizadora $s 1$ do vacA e ocorrência de úlcera péptica tem sido demonstrada por alguns autores $(3,28$, 33). A ligação entre $\operatorname{cag} A$ e atividade citotóxica não é bem explicada, mas a maioria das amostras cagA positivas apresenta o alelo $s 1$ do $\operatorname{Vac} A(28,33)$. Por outro lado, amostras $\operatorname{cag} A$ negativas geralmente têm o alelo s2 do vacA. Entretanto a razão para a existência desta associação ainda não é clara (5), uma vez que não existe ligação física entre os dois genes no cromossomo bacteriano. Não se sabe, também, se a associação está presente em amostras isoladas de pacientes de diferentes regiões do mundo.

Estudos sobre a freqüência destes marcadores e sua relação com as diversas doenças do aparelho digestivo em crianças são escassos em todo o mundo. No Brasil, onde a aquisição de $H$. pylori ocorre, na maioria das vezes, precocemente na infância, em especial na população de baixo nível socioeconômico, estudos desta natureza são praticamente inexistentes (15). Além disto, não existem relatos sobre a associação entre a presença de cagA e dos alelos s1 e m1 do vacA em amostras de H. pylori isoladas no Brasil, tanto em crianças como em adultos.

\section{Objetivos}

Os objetivos deste estudo foram investigar a prevalência de $\operatorname{cag} A$ e de alelos vacA em amostras de $H$. pylori isoladas 
de crianças com e sem úlcera duodenal, relacionar estes achados com as doenças apresentadas pelos pacientes $\mathrm{e}$ pesquisar a existência de associação entre os dois marcadores moleculares de patogenicidade.

\section{Pacientes e métodos}

Foram estudados 65 pacientes ( 33 do sexo feminino, faixa etária de 1 a 17 anos, média de idade de 10,2 anos), com cultura positiva para $H$. pylori, que haviam sido encaminhados, entre 1993 e 1997, ao Serviço de Endoscopia Pediátrica do Hospital das Clínicas da UFMG para esclarecimento de manifestações clínicas relativas ao trato digestivo alto. Consentimento informado foi obtido dos pais de todos os pacientes. Nenhuma criança encontrava-se em uso de antiinflamatórios não-esteróides, antagonistas de receptores $\mathrm{H} 2$, inibidores de bomba de prótons ou drogas antimicrobianas nos 30 dias anteriores à obtenção do material. Pacientes com distúrbios de coagulação ou sangramento ativo à endoscopia, com perfuração e/ou hemorragia gástrica, com impedimento anatômico à endoscopia, encaminhados para esclerose de varizes ou dilatação de estenose de esôfago, com sedação insuficiente ou apresentando reações colaterais graves às drogas utilizadas para sedação ou anestesia, ou com doenças ou disfunções graves não foram submetidos a endoscopia.

Entre os 65 pacientes estudados, 24 apresentavam úlcera duodenal à endoscopia; ulcerações gástricas ou duodenais não foram observadas ao exame endoscópico de 41 crianças.

Fragmentos de mucosa gástrica foram obtidos, por endoscopia, nas regiões da pequena curvatura do antro e grande curvatura do corpo gástrico, para diagnóstico da infecção por $H$. pylori, realizado por exame direto de esfregaços corados por carbolfucsina, teste da urease préformada e cultura em meio Belo Horizonte (24). Após identificação do microrganismo, parte do crescimento foi removido com swab estéril e transferido para um tubo de microcentrífuga contendo $500 \mu \mathrm{l}$ de água quimicamente pura. A suspensão foi centrifugada a $6.000 \times \mathrm{g}$ por cinco minutos e o sobrenadante foi descartado. O pellet foi mantido em freezer a $-80^{\circ} \mathrm{C}$ até o momento da extração de DNA, que foi realizada por meio de tratamento com proteinase $\mathrm{K}$ e separação com fenolclorofórmio, como descrito por Fox et al. (14).

As reações de amplificação foram realizadas como descrito a seguir: 50ng a 100ng de DNA extraídos das amos- tras bacterianas foram adicionados a uma mistura de reação de $50 \mathrm{ml}$ (volume final) contendo Tris- $\mathrm{HCl} 10 \mathrm{mM}(\mathrm{pH}$ $8,3), \mathrm{KCl} 50 \mathrm{mM}, \mathrm{MgCl}_{2}$ 1,5mM, deoxinucleotídeos ( $200 \mu \mathrm{M}$ cada), 2,5U de Taq DNA polimerase e $0,2 \mu \mathrm{M}$ de cada primer, como especificado para cada reação.

Para amplificação de um fragmento de 411 pares de base do ureA, gene espécie-específico presente em todas as amostras de $\mathrm{H}$. pylori, foram empregados os primers e a metodologia descritos por Clayton et al. (8). Uma amostra de Escherichia coli (isolada de paciente com infecção do trato urinário) foi empregada como controle negativo, a amostra de $H$. pylori ATCC 49503, como controle positivo e água destilada, como controle negativo interno da reação.

A amplificação da seqüência sinalizadora e da região média do vacA foi realizada utilizando-se os primers e a metodologia descritos por Atherton et al. (1, 2). As amostras de H. pylori ATCC 49503 (s1-m1), 435-95 (identificada no Laboratório de Biologia Molecular como s1-m2) e Tx30A (s2-m2) foram empregadas como controles para detecção dos alelos do vacA. Água destilada foi empregada como controle negativo interno da reação.

Para detecção do cagA, primers e metodologia propostos por Tummuru et al. (26), que amplificam um fragmento de 349 pares de base, foram utilizados. As amostras ATCC 49503 e Tx30A e água destilada foram empre- gadas como controles positivo e negativo e como controle negativo interno da reação, respectivamente.

Os produtos amplificados foram detectados, por meio de eletroforese em gel de agarose a 1,2\%, em transiluminador de luz ultravioleta, após coloração com brometo de etídio na concentração de $2,5 \mu \mathrm{g} / \mathrm{ml}$, empregando-se marcador de peso molecular de 50bp ou 100bp (pharmacia biotech).

A análise estatística foi feita empregando-se o teste de $X^{2}$, com correção de Yates, ou o teste exato de Fisher, quando indicado. $O$ nível de significância foi estabelecido para $p \leq 0,05$.

\section{Resultados}

Apenas amostras ureA positivas foram incluídas neste estudo. Dez pacientes com infecção mista (infecção por amostras da bactéria apresentando diferentes genótipos vacA) não foram incluídos nesta análise.

Dos 55 pacientes com monoinfecção pelo microrganismo, 19 apresentavam úlcera duodenal e 36 não tinham úlcera gástrica ou duodenal. 
O alelo s1 foi identificado em amostras obtidas de 40 pacientes (72,7\%): 19 (100\%) com úlcera duodenal e 21 $(58,3 \%)$ sem úlcera. Amostras s2 foram detectadas apenas em pacientes sem úlcera (Tabela 1).

Amostras $\mathrm{m} 1$ foram detectadas em 34 (61,8\%) pacientes, 16 (84,2\%) com úlcera duodenal e 18 (50\%) sem úlcera. $\mathrm{O}$ alelo $\mathrm{m} 2$ foi identificado em amostras obtidas de 20 $(36,4 \%)$ pacientes, três $(15,8 \%)$ com úlcera duodenal e 17 $(47,2 \%)$ sem úlcera. Amostra híbrida m1,2 foi identificada em apenas um paciente $(1,8 \%)$ (Tabela 1$)$.

Associação estatisticamente significativa foi observada entre amostras de $H$. pylori apresentando alelo s1 ( $p=0,0029 ;$ OR e IC95\% não-calculáveis) ou alelo m1 $(p=0,037 ; \mathrm{OR}=5,04 ; \mathrm{IC} 95 \%=1,11$ a 30,87$)$ e úlcera duodenal. O genótipo s1-m1 foi mais freqüentemente observado em pacientes com úlcera duodenal ( $p=0,037$; OR = 5,04; IC95\%=1,11 a 30,87) (Tabela 1).

O cagA foi identificado em $38(69,1 \%)$ amostras de $H$. pylori, sendo $18(94,7 \%)$ isoladas de crianças com úlcera duodenal e $20(55,6 \%)$ de pacientes sem úlcera. Das 17 $(30,9 \%)$ amostras cagA negativas, uma $(5,3 \%)$ foi isolada de paciente com úlcera duodenal e $16(44,4 \%)$, de pacientes sem úlcera (Tabela 2).

Genótipos do vacA em amostras de H. pylori isoladas de 19 crianças com Tabela 1 úlcera duodenal e de 36 sem úlcera

\begin{tabular}{lccc}
\hline Genótipo & $\begin{array}{c}\text { Com úlcera } \\
\text { duodenal - } \mathbb{N}^{0}(\%)\end{array}$ & $\begin{array}{c}\text { Sem úlcera } \\
\mathbf{N}^{0}(\%)\end{array}$ & $\begin{array}{c}\text { Total } \\
\mathbb{N}^{0}(\%)\end{array}$ \\
s1-m1 & $16(84,2)$ & $18(50)$ & $34(61,8)$ \\
s1-m2 & $3(15,8)$ & $2(5,5)$ & $5(9,1)$ \\
s1-m1,2 & - & $1(2,8)$ & $1(1,8)$ \\
s2-m2 & - & $15(41,7)$ & $15(27,3)$ \\
\hline
\end{tabular}

Distribuição de cagA em amostras de H. pylori isoladas de 19 crianças com Tabela 2 úlcera duodenal e de 36 sem úlcera

\begin{tabular}{lccc}
$\begin{array}{l}\text { Genótipo } \\
\text { cagA }\end{array}$ & $\begin{array}{c}\text { Com úlcera } \\
\text { duodenal }-\mathbb{N}^{0}(\%)\end{array}$ & $\begin{array}{c}\text { Sem úlcera } \\
\mathbb{N}^{0}(\%)\end{array}$ & $\begin{array}{c}\text { Total } \\
\mathbb{N}^{0}(\%)\end{array}$ \\
Positivo & $18(94,7)$ & $20(55,6)$ & $38(69,1)$ \\
Negativo & $1(5,3)$ & $16(44,4)$ & $17(30,9)$ \\
Total & $19(100)$ & $36(100)$ & $55(100)$ \\
\hline
\end{tabular}

Foi observada associação significativa entre úlcera duodenal e infecção com amostras cagA positivas ( $p=0,073$; $\mathrm{OR}=14,40 ; \mathrm{IC} 95 \%=1,80$ a 636,67) (Tabela 2).

Entre os 55 pacientes com monoinfecção, o alelo s1 foi identificado em todas as 38 amostras cagA positivas da bactéria e em duas $(11,8 \%)$ amostras cagA negativas. $\mathrm{O}$ alelo $\mathrm{s} 2$ foi detectado apenas em amostras cagA negativas ( $n=15$; $88,2 \%)$. Associação estatisticamente significativa foi observada entre a presença de $\operatorname{cag} A$ e a região sinalizadora s1 do $\operatorname{vac} A\left(p=10^{-7} ;\right.$ OR não-calculável) (Tabela 3).

$O$ alelo $\mathrm{m} 1$ foi detectado em $32(84,2 \%)$ amostras cagA positivas e em duas $(11,8 \%)$ cagA negativas. $\mathrm{O}$ alelo $\mathrm{m} 2$ foi encontrado em $15(88,2 \%)$ amostras cagA negativas e em cinco $(13,2 \%)$ cagA positivas. Foi observada associação estatisticamente significativa entre presença do alelo $\mathrm{m} 1$ e de $\operatorname{cagA}\left(p=10^{-7} ; \mathrm{OR}=48 ;\right.$ IC $95 \%=7,06$ a 492,9$)$ (Tabela 3).

Entre os 19 pacientes com úlcera duodenal, 18 (94,7\%) mostraram-se colonizados por amostras cagA positivas e que apresentavam o alelo $s 1$ do vacA. Nas crianças sem úlcera, apenas $20(55,6 \%)$ apresentaram amostras com o genótipo cagA positivo/alelo s1 do vacA. Associação estatisticamente significativa foi observada entre amostras de $H$. pylori $1 /$ cagA positivas e presença de úlcera duodenal $(p=0,005)$.

\section{Discussão}

A infecção por Helicobacter pylori é uma das infecções bacterianas mais freqüentes em todo o mundo, estando consistentemente acompanhada por reação inflamatória

Associação entre cagA e alelos do vacA em amostras de $H$. pylori isoladas de

Tabela 3 crianças com monoinfecção

\begin{tabular}{lcc}
\hline $\begin{array}{l}\text { Alelos } \\
\text { vacA }\end{array}$ & $\begin{array}{c}\text { cagA positivo } \\
\mathrm{N}^{0}(\%)\end{array}$ & $\begin{array}{c}\text { cagA negativo } \\
\mathbb{N}^{0}(\%)\end{array}$ \\
$\begin{array}{l}\text { Região sinalizadora } \\
\text { s1 }\end{array}$ & $38(100)$ & $2(11,8)$ \\
s2 & - & $15(88,2)$ \\
\hline Total & 38 & 17 \\
\hline Região média & & \\
m1 & $32(84,2)$ & $2(11,8)$ \\
m1,2 & $1(2,6)$ & - \\
m2 & $5(13,2)$ & $15(88,2)$ \\
\hline Total & 38 & 17 \\
\hline
\end{tabular}


da mucosa gástrica. Uma vez adquirida, a infecção persiste, na maior parte dos indivíduos, por anos, décadas, ou, possivelmente, por toda a vida se não tratada com drogas antimicrobianas (13). Na maioria das vezes, a infecção é assintomática ou o paciente apresenta apenas manifestações clínicas discretas. Apenas uma minoria desenvolve úlcera péptica (20), importante causa de morbidade em todo o mundo, ou gastrite crônica atrófica, considerada um fator de risco para o desenvolvimento de adenocarcinoma gástrico $(13,31)$.

Algumas características das amostras de H. pylori parecem estar associadas à evolução da infecção para doença mais grave. Entre elas, alguns genótipos, como alelos $\mathrm{s} 1 \mathrm{e}$ m1 de vacA e cagA, têm sido considerados marcadores de patogenicidade por estarem associados à produção de citotoxina e à indução de lesão epitelial e de reação inflamatória mais intensas, estando freqüentemente associados, na maioria dos países, com evolução da infecção para o desenvolvimento de doenças mais graves, como doença ulcerosa péptica e adenocarcinoma gástrico $(3,9$, $24,30,33$ ).

A distribuição geográfica dos alelos do vacA não é uniforme (27). A freqüência de $s 1$ observada na população examinada neste estudo $(72,7 \%)$ é semelhante à encontrada no leste e no norte da Europa $(73,5 \%)$ e nas Américas Central e do Sul $(71,4 \%)(27,32)$. Na França, na Itália, no Canadá e nos Estados Unidos a freqüência do alelo é de, aproximadamente, $60 \%$, e, no Japão, na África do Sul e no México, de $85 \%$ a $90 \%(19,27,32,33)$. Por outro lado, a distribuição dos alelos $m$ é mais homogênea e, de uma maneira geral, metade das amostras é m1 e a outra metade, m2 (27). No nosso meio, entretanto, amostras $\mathrm{m} 1(61,8 \%)$ são mais comuns que as do tipo $\mathrm{m} 2$ (36,4\%).

Resultados de estudos realizados na década de 90 sugerem que o genótipo $\mathrm{s} 1-\mathrm{m} 1$ do vacA possa ser usado como um marcador de amostras mais virulentas de $H$. pylori $(1,3)$, em conformidade com o fato de que o alelo s1 está relacionado à produção da citotoxina vacuolizante e que o alelo $\mathrm{m} 1$ está associado com produção de maior quantidade da toxina (1). No presente estudo, foi observada associação entre presença de amostras s1-m1 e úlcera duodenal $(p=0,037)$, confirmando resultados descritos por Evans et al. (12) para amostras de H. pylori obtidas de adultos brasileiros. Temos conhecimento de apenas dois estudos, desenvolvidos em pacientes pediátricos com úlcera duodenal, que caracterizam o vacA, por PCR, em suas seqüências sinalizadora e média $(6,15)$. Çelik et al. $(6)$ estudaram a freqüência dos alelos $s 1, \mathrm{~s} 2, \mathrm{~m} 1 \mathrm{e} \mathrm{m} 2 \mathrm{em}$ amostras de $H$. pylori obtidas de 29 crianças com gastrite e três com úlcera duodenal. O genótipo $\mathrm{s} 1$-m1 foi observado em $66,7 \%$ das crianças com úlcera duodenal e em $41,4 \%$ dos pacientes com gastrite, não tendo sido observada associação entre o genótipo e úlcera duodenal, provavelmente devido ao pequeno número de crianças com úlcera duodenal incluídas no estudo. Diferentemente, Gusmão et al. (15) observaram a associação do genótipo s1-m1 com o desenvolvimento de úlcera duodenal; os autores, entretanto, não fazem referência ao cagA.

De forma semelhante ao que se observa na população adulta para $v a c A$, a freqüência de amostras cagA positivas varia de uma região geográfica para outra. Embora praticamente todas as amostras isoladas de pacientes colonizados por $\mathrm{H}$. pylori apresentem o gene nos países asiáticos $(22,32,33)$, no restante do mundo esta distribuição é heterogênea. Em grande parte dos países da Europa Ocidental e nos Estados Unidos, a freqüência de amostras cag $A$ positivas varia entre $59 \%$ e $75 \%(28,30)$; na Itália e em Portugal, as taxas são superiores a $80 \%$ (28) e, no México, praticamente $100 \%$ dos indivíduos apresentam-se colonizados por amostras que carreiam o gene (19).

No paciente pediátrico, a presença do gene, demonstrada de forma direta ou por meio de reações sorológicas, foi observada em $89 \%$ das crianças com gastrite grave na França (16), em aproximadamente $80 \%$ das crianças assintomáticas na China (18) e em 100\% das crianças com úlcera péptica na Austrália (18) e no Brasil (23). Apesar das diferenças observadas pelos autores, que podem estar relacionadas à amostragem e à região geográfica, entre outros motivos, a maioria dos resultados demonstra maior freqüência de amostras cagA positivas em pacientes com úlcera péptica ou carcinoma gástrico $(12,24,32)$.

No presente estudo, amostras cagA positivas foram identificadas em $69,1 \%$ das crianças, freqüência similar à observada em adultos em diversos países ocidentais. Nas crianças com úlcera duodenal, o gene foi detectado em $94,7 \%$ das amostras estudadas, confirmando a observação de diferentes autores, em diversas regiões do mundo, de que amostras $\operatorname{cag} A$ positivas são mais freqüentemente isoladas de pacientes com esta afecção $(16,19,23,24$, $28,30,32$ ).

Em algumas populações, o cagA ou o genótipo s1-m1 do vacA não podem ser usados como marcadores de amostras mais virulentas de $H$. pylori $(18,21,22,32,33)$. Assim, uma análise de vários fatores de virulência bacterianos, além de fatores relacionados ao ambiente e ao hospedeiro, 
deve ser realizada para se avaliar o risco de desenvolvimento de doenças graves associadas à infecção pelo microrganismo.

Recentemente, Van Doorn et al. (28) relataram que, em adultos holandeses, amostras de $H$. pylori com genótipo s1/cagA positivo podem ser consideradas mais virulentas, uma vez que tais amostras são predominantemente encontradas em pacientes com úlcera péptica, resultado que vem sendo confirmado por outros autores em pacientes adultos $(12,19,32)$. Resultados semelhantes foram observados no presente estudo: a presença do genótipo s1/cagA positivo foi observada em cerca de $95 \%$ dos pacientes com úlcera duodenal $(p=0,005)$. No que se refere à região média do gene, grande parte dos autores não faz referência à existência de associação dos alelos $\mathrm{m} 1$ ou $\mathrm{m} 2$ com cagA. Alta freqüência do genótipo $\mathrm{m} 1 /$ cagA positivo foi observada neste estudo $(89,5 \%)$, como relatado por Atherton et al. (1) e Evans et al. (12), para adultos.

A relação entre os genótipos discutidos acima é ainda pouco conhecida. Embora vários estudos tenham demonstrado a existência de relação entre $\operatorname{cag} A$ e $\operatorname{vac} A$, a razão pela qual estes dois elementos genéticos, que não apresentam qualquer ligação física no cromossomo de $\mathrm{H}$. pylori (5), estão tão fortemente associados não é, ainda, clara. A associação pode ser epidemiológica, existindo populações clonais de H. pylori cuja distribuição não é casual (27). É possivel, ainda, que tais associações tenham uma base funcional ainda não-explicada.

Finalizando, a investigação do padrão genotípico de amostras de $H$. pylori em crianças, no nosso meio, é importante por apresentar relevância clínica, uma vez que a maioria dos pacientes com úlcera duodenal apresenta-se colonizada por amostras de H. pylori carreando o genótipo s1/cagA positivo. Além disso, como demonstrado por Van Doorn et al. (29), a resposta ao tratamento com antimicrobianos está relacionada ao genótipo do microrganismo: pacientes que carreiam amostras do tipo s1/cagA positivo apresentam taxas de cura da infecção mais elevadas.

\section{Conclusões}

Os alelos $s 1$ da seqüência sinalizadora e $\mathrm{m} 1$ da região média do vacA são os mais freqüentemente observados, no nosso meio, nas amostras de $H$. pylori isoladas de crianças. De forma semelhante, o cagA está presente na maioria das amostras isoladas, especialmente naquelas obtidas de pacientes com úlcera duodenal.

O genótipo cagA positivo está fortemente associado com a presença dos alelos $s 1$ e $\mathrm{m} 1$ do vacA, como observado em outras regiões do mundo.

O genótipo $\mathrm{s} 1-\mathrm{m} 1 /$ cagA positivo foi o mais freqüentemente observado nas crianças estudadas e mostrou-se associado à presença de úlcera duodenal. Assim, a genotipagem de amostras do microrganismo parece ser clinicamente relevante no nosso meio, podendo contribuir para predizer tanto a evolução da infecção por H. pylori como a reposta do paciente ao tratamento com antimicrobianos.

\section{Agradecimentos}

Nossos agradecimentos ao prof. dr. Evanguedes Kalapothakis, que cedeu a Taq DNA polimerase empregada neste estudo.

\section{Referências}

I.Atherton, J.C. et al. Mosaicism in vacuolating cytotoxin alleles of Helicobacter pylori: association of specific vacA types with cytotoxin production and peptic ulceration. J Biol. Chem., 270: 1777|-7, 1995

2. Atherton, J.C. et al. Simple and accurate PCR-based system for typing vacuolating cytotoxin alleles of Helicobacter pylori.J. Clin. Microbiol., 37: 2979-82, 1999

3. Atherton, J.C. et al. Clinical and pathological importance of heterogeneity in vacA, the vacuolating cytotoxin gene of Helicobacter pylori. Gastroenterology, I I 2: 92-9, 1997.

4. Boren, T. et al.Attachment of Helicobacter pylori to human gastric epithelium mediated by blood group antigens. Science, 262: 1892-5, 1993.
5. Bukanov, N.O. \& Berg, D.E. Ordered cosmid library and highresolution physical-genetic map of Helicobacter pylori strain. Mol. Microbiol., I I: 509-23, 1994.

6. Çelik, J.; Su, B. \& Trén, U. Virulence and colonization-associated properties of Helicobacter pylori isolated from children and adolescents. J. Infect Dis., 177: 247-52, 1998.

7. Censini, S. et al. Cag, a pathogenicity island of Helicobacter pylori, encodes type I-specific and disease-associated virulence factors. Proc. Natl. Acad. Sci. USA, 93: 14648 53,1996

8. Clayton, C.L. et al. Sensitive detection of Helicobacter pylori by using polymerase chain reaction. J. Clin. Microbiol., 30: 192 200, 1992. 
9. Covacci, A. et al. Molecular characterization of 128-kDa immunodominant antigen of Helicobacter pylori associated with cytotoxicity and duodenal ulcer. Proc. Natl. Acad. Sci. USA, 90: 5791-95, 1993.

10. Cover,T.L.; Halter, S. \& Blaser, M.J. Characterization of HeLa cell vacuoles induced by Helicobacter pylori broth culture supernatant. Human Pathol., 23: 1004- 10, 1992.

I I. Eidt, S.; Stolte, M. \& Fischer, R. Helicobacter pylori gastritis and primary gastric non-Hodgkin's lymphomas. J. Clin. Pathol., 47: 436-9, 1994.

12. Evans, D.G. et al. Helicobacter pylori cagA status and $s$ and $m$ alleles of vacA in isolates from individuals with a variety of H. pylori-associated gastric disease.J. Clin. Microbiol., 36:3435-7, 1998.

1 3. Forman, D. et al.Association between infection with Helicobacter pylori and risk of gastric cancer: evidence from a prospective investigation. Br. Med. J., 302: I302-5, 199 I.

14. Fox, J.G. et al. Intracellular Campylobacter-like organism from ferrets and hamsters with proliferative bowel disease is a Desulfovibrio sp. J. Clin. Microbiol., 32: 1229-37, 1994.

15. Gusmão,V.R. et al. VacA genotypes in Helicobacter pylori strains isolated from children with and without duodenal ulcer in Brazil. J. Clin. Microbiol., 38: 2853-7, 2000.

16. Husson, M.O. et al. Importance in diagnosis of gastritis of detection by PCR of the cagA gene in Helicobacter pylori strains isolated from children. J. Clin. Microbiol., 33: 3300-3, 1995.

17. Marshall, B.J. \& Warren, J.R. Unidentified curved bacilli in the stomach of patients with gastritis and peptic ulceration. Lancet, I (8390): | 3| |-5, | 984.

18. Mitchell, H.M. et al. The prevalence of antibody to cagA in children is not a marker for specific disease. J. Pediatr. Gastroenterol., 28: 7I-5, 1999.

19. Morales-Espinosa, R. et al. Colonization of Mexican patients by multiple Helicobacter pylori strains with different vacA and cagA genotypes. J. Clin. Microbiol., 37: 300 I-4, 1999.

20. National Institute of Health Consensus Conference. Helicobacter pylori in peptic ulcer disease. NIH Consensus Development Panel on Helicobacter pylori in peptic ulcer disease. JAMA, 272: 65-9, 1994.
21. Ogura, K. et al. High prevalence of cytotoxin positive Helicobacter pylori in patients unrelated to the presence of peptic ulcers in Japan. Gut, 41: 463-8, 1997.

22. Pan, Z.J. et al. Equally high prevalence of infection with cagApositive Helicobacter pylori in Chinese patients with peptic ulcer disease and those with chronic gastritis-associated dyspepsia. J. Clin. Microbiol., 35: I344-7, 1997.

23. Queiroz, D.M.M. et al. Factors associated with Helicobacter pylori infection by a cagA-positive strain in children. J. Infect Dis., 1 81: 626-30, 2000.

24. Queiroz, D.M.M. et al. cagA positive Helicobacter pylori and risk for developing gastric carcinoma in Brazil. Int. J. Cancer, 78: 135-9, 1998.

25. Tee, W.; Lambert, J.R. \& Dwyer, B. Cytotoxin production by Helicobacter pylori from patients with upper gastrointestinal tract diseases. J. Clin. Microbiol., 33: I203-5, 1995.

26. Tummuru, M.K.R.; Cover,T.L. \& Blaser, M.J. Cloning and expression of a high-molecular-mass major antigen of Helicobacter pylori: evidence of linkage to cytotoxin production. Infect. Immun., 6 I: |799-1809, 1993.

27. Van Doorn, L.J. et al. Geographic distribution of vacA allelic types of Helicobacter pylori. Gastroenterology, I | 6:823-30, 1999.

28. Van Doorn, L.J. et al. Clinical relevance of cagA, vacA, and iceA status of Helicobacter pylori. Gastroenterology, I | 5:5866, 1998.

29. Van Doorn, L.J. et al. Importance of Helicobacter pylori cagA and vacA status for efficacy of antibiotic treatment. Gut., 46: 321-6, 2000.

30. Warburton, V.J. et al. Clinical and histological association of cagA and vacA genotypes in Helicobacter pylori gastritis. J. Clin. Pathol., 51:55-61, 1998.

31. World Health Organization. The evaluation of carcinogenic risks to humans. Lyon: International Agency for Research on Cancer, 1994. Monograph no 61 .

32. Yamaoka,Y. et al. Relationship between Helicobacter pylori iceA, cagA, and vacA status and clinical outcome: studies in four different countries. J. Clin. Microbiol., 37: 2274-9, 1999.

33. Yamaoka,Y. et al. Relationship of vacA genotypes of Helicobacter pylori to cagA status, cytotoxin production, and clinical outcome. Helicobacter, 3: 24I-53, 1998. 